\title{
Entrevista
}

\section{Josette Féral - Professora e pesquisadora teatral}

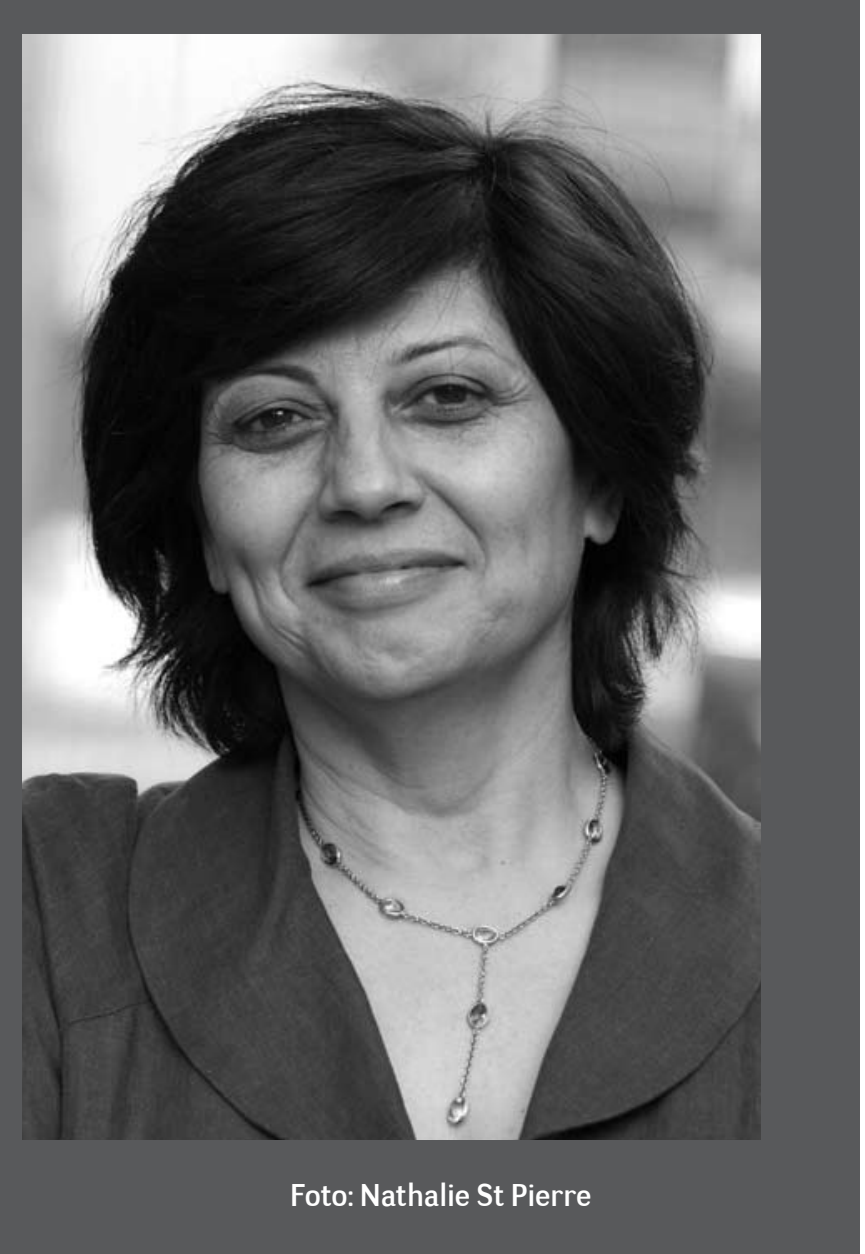

Julia Guimarães ${ }^{1}$ e Leandro Silva Acácioº

Conhecida por seus estudos sobre os conceitos de teatralidade e performatividade, a pesquisadora franco-canadense Josette Féral, esteve em São Paulo em novembro do ano passado (2010), durante o VI Congresso da ABRACE (Associação Brasileira de Pesquisa e Pós-Graduação em Artes Cênicas), para realizar a conferência O Real na Arte: a Estética do Choque. Professora do Departamento de Teatro da

Universidade de Québec, em Montreal, autora e organizadora de diversos livros e artigos, Féral discutiu a presença do real na arte contemporânea, com recorte em obras artísticas que exploram especificamente o instante da morte no interior das próprias criações.

Na conferência, a autora questionou os limites éticos e estéticos dessa exploração, além de discutir seus efeitos sobre o público. Como exemplo, utilizou três trabalhos: Rwanda 94 (2000), do Le Groupov;3 La Batalla de Chile (1979), dirigido por Patricio Guzmán4 e Theatre of the World (1993), de Huang Yong Ping. ${ }^{5}$

Enquanto o primeiro é um espetáculo teatral que explora, no vídeo, uma cena de morte durante o genocídio ocorrido em
Ruanda, na África, La Batalla de Chile é um documentário sobre o golpe contra o presidente Salvador Allende, que resultou na ascensão de Pinochet. Nele, o cameraman argentino Leonardo Henrichsen filma sua própria morte, ao levar um tiro enquanto registrava cenas do golpe. Já o trabalho de Ping exibe um grande viveiro onde escorpiões, centopeias, lagartixas e pequenas cobras são colocadas num mesmo espaço e ali iniciam um duelo com mortes. 
A entrevista com Josette Féral ocorreu em São Paulo, no dia seguinte ao de sua conferência, em dois espaços distintos: no restaurante do hotel onde estava hospedada e na cantina da UNESP (Universidade Estadual Paulista), onde ocorreu o congresso. Entre um café e outro, a pesquisadora partilhou suas inquietações atuais sobre o teatro contemporâneo ao aprofundar os tópicos levantados na conferência, em entrevista traduzida do francês ao português pelos pesquisadores teatrais Alexandre Pieroni Calado e Alice. Sua primeira obra traduzida para o português acaba de ser publicada: o livro Encontros com Ariane Mnouchkine - Erguendo um Monumento ao Efêmero (Ed. SENAC São Paulo).

\section{$O$ que te levou a querer estudar o conceito da estética do choque?}

O que me interessava, inicialmente, era analisar a emergência do real no teatro. E, como falei na conferência, isso é algo bem frequente no teatro atual. Existem diferentes manifestações do real em cena, mas penso que há uma forma dessa aparição que traz um problema, que é quando se mata alguém, quando se trata da questão da morte. Recebi um pedido para trabalhar sobre o espetacular com relação aos atentados de 11 de Setembro e o que me interessava era o discurso que acabou sendo criado em volta dos atentados. $\mathrm{Na}$ última vez que vim a São Paulo, tive uma conversa com Richard Schechner ${ }^{6}$ por skype e ele havia descoberto que a arte

1 Julia Guimarães é jornalista e mestranda em Artes Cênicas pela Escola de Belas Artes da UFMG.

2 Leandro da Silva Acácio é ator e mestrando em Artes Cênicas pela Escola de Belas Artes da UFMG

3 Le Groupov: coletivo de artistas de diferentes áreas - teatro, vídeo, música etc - e nacionalidades fundado em 1980 pelo francês Jacques Delcuvellerie.

4 Patricio Guzman: documentarista chileno.

5 Huang Yong Ping (1954): artista visual francês de origem chinesa. $\mathrm{O}$ trabalho de Yong Ping combina várias linguagens oriundas de diferentes culturas. Dentre suas várias influências, é possível destacar o Movimento Dadaísta e a numerologia chinesa. poderia ter um lado negativo, poderia ser má. Para mim, era interessante, mas bem surpreendente essa frase. E eu também conhecia o trabalho do Huang Yong Ping e ele me incomodava. Então, decidi trabalhar nos limites do que eu, como espectadora, podia aceitar. E me perguntava como o espectador podia legitimar essas formas 'más' de arte. Perguntava-me se todas as artes, por serem artes, se tornavam legítimas, e não estava certa disso. E penso que hoje existem questões de ética que se colocam nessa discussão da arte.

Na palestra, vocêfalou dessa dimensão obscena que existe na exploração da violência real na arte e que coloca em xeque justamente questões morais e éticas. No entanto, existem artistas que exploram a violência real em cena até mesmo como um ato político. Como você percebe essa contradição?

Eu não pensei ainda na violência em si, não fiz um trabalho sobre a violência, mas sobre a transformação do evento violento real colocado na cena. Eu me pergunto: em que momento temos o direito de utilizar as catástrofes humanas de forma artística, esquecendo as mortes? A afirmação de Stockhausen" de que o 11 de Setembro seria "a mais bela obra de arte" causou esse problema. A questão não é a violência em si, porque ela existe tanto na cena quanto na vida. Mas quando temos o direito de usar a violência real para transformá-la em obra de arte? Esse é o problema. Porque os artistas sempre utilizaram a violência em cena. Na própria performance, a violência já apareceu tanto em relação aos próprios performers quanto em relação a outras coisas. Trabalhos de muitos artistas têm bastante sangue. E quando falo de violência na cena, me refiro a eventos reais, de quando alguém morre na sua frente.

6 Richard Schechner é pesquisador, professor da New York University e diretor de teatro. Fundador e editor da revista The Drama Review, publicada pela NYU.

7 Karlheinz Stockhausen (1929-2007). Compositor alemão de música contemporânea. Foi colega de Pierre Boulez e ambos estudaram com o compositor e organista Olivier Messiaen. 
Mas nos exemplos que mostrei na palestra, existem diferenças entre os dois primeiros e o terceiro. Os dois primeiros não colocam para mim problemas éticos e estéticos. Eles são trazidos deforma respeitosa.Já oterceiro (de Ping), que não tem especificamente a ver com o ser humano, me causa uma repulsa. Ele coloca questões éticas para mim, mesmo sendo um trabalho com animais, porque parece completamente gratuito. Eu entendo qual foi o argumento do artista, mas acho bem extremo ter que passar pelo viveiro (onde ficam os bichos na obra de Ping) para concretizar esse pensamento. Mas não é sobre a violência que eu trabalho, eu trabalho sobre a estética. Sobre o que entra ou não nesse terreno e como reagimos quanto a isso.

\section{Alguns autores brasileiros relacionam a presença do real na cena contemporânea a uma incapacidade de simbolizar eventos que seriam por demais traumáticos. Por isso deslocam fragmentos desse real em estado bruto para a cena. Você percebe essa relação em seu estudo sobre a estética do choque?}

Eu não estou certa se seria por uma incapacidade de simbolizar. Acho que trazer elementos brutos na cena causa sempre um impacto muito grande para o espectador. Porque estamos tão habituados à violência que talvez a violência simbólica não faça mais efeito sobre nós, em alguns casos. Mas também acho que a violência real traz uma sensação diferente porque a sentimos no próprio corpo. Talvez seja a manifestação do nosso individualismo engrandecido. Porque ela nos faz reagir por intermédio do nosso corpo e não do nosso intelecto. E o corpo é o que a gente tem de mais individual, de mais pessoal.
A violência simbólica cria uma ligação coletiva, mas a violência real manifestada na cena entra na gente. Ela não se divide, nós a recebemos individualmente. Pode ser uma possível interpretação, não sei.

Na palestra, você fala de uma leitura dos diferentes pontos da natureza do olhar sobre eventos extremos, que estão no livro do Paul Ardenne. ${ }^{8}$ Na sua opinião, o que eles sinalizam em relação a essa recepção da estética do choque pelos espectadores?
Mas quando temos

o direito de usar a violência real para transformá-la em obra de arte? é perceber porque olhamos essas coisas. E o que a gente sente ao olhar, o que nos acorda em si. Vou voltar aos princípios do Paul Ardenne. Um deles é que a gente gosta de olhar aquilo a que não estamos acostumados. O segundo está ligado à exterioridade. É muito importante que a gente sempre fique fora do evento. Nos dois exemplos que uso na conferência, não estamos no Chile, nem em outro lugar. O impacto desse evento é ainda mais forte, porque estamos na segurança, num lugar tranquilo, enquanto os outros estão na insegurança. A gente não precisa salvar nossa pele. Se estivéssemos com os militares, estaríamos pensando em fugir, em nos salvar, e não na morte do cameraman. O terceiro é o desejo de ver eventos extremos, um pouco como no circo romano, eu penso. O impactante nos exemplos que dei é que eles tocam a morte. É a diferença que faz Ardenne sobre os eventos extremos e os

8 Paul Ardenne (1956) é professor de história na Universidade de Amiens, e é também crítico de arte e curador no campo da arte contemporânea. Autor de vários ensaios, tais como Extrême: esthétiques de la limite dépassée, Flammarion, 2006. 
superlativos. Os últimos seriam eventos impressionantes, eles nos tocam, mas não da mesma forma que os eventos extremos, como no espetáculo "Inferno" de Castelucci, ${ }^{9}$ que mostrei na palestra. Você olha o alpinista e acha que ele vai parar de subir com $5 \mathrm{~m}$ de altura, mas ele continua. Isso é superlativo, porque está fora do nosso habitual e nos deixa impressionado. Também existe o superlativo de rejeição, como em um espetáculo que o Castelucci coloca um contorcionista cujo corpo se desarticula em cena.

Na palestra, você diferencia a presença do real nas performances dos anos 1960 com a de agora, que estaria mais ligada à interrupção da ficção, de quebra com o contrato inicial estabelecido com o público. O que muda entre uma experiência e outra no que se refere aos efeitos dessa presença?

O caminho da performance era pela estética e pela política, mas bem mais pela estética. Ela procurava tirar a arte dos lugares habituais deconsumo, dos circuitos institucionais. Ela modificava profundamente natureza do produto artístico, insistia no aspecto processual e não no aspecto produto. $\mathrm{O}$ que os artistas mostravam não era o produto final e, sim, o processo. E ela

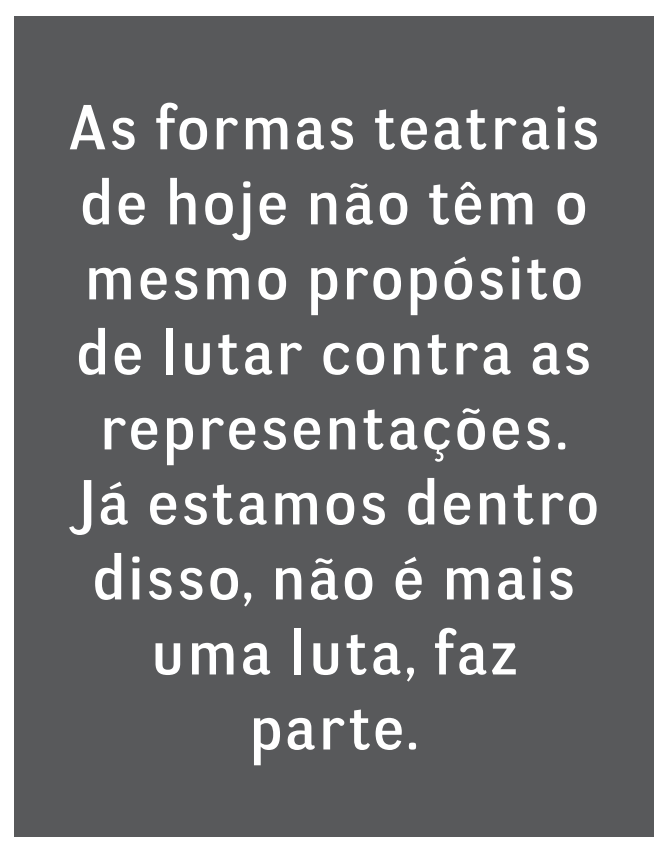
procurava reinstituir a presença. Era importante essa procura da presença porque a performance buscava lutar contra a representação. E fazer do espetáculo uma presentação. Énesse sentido que ela era política. As formas teatrais de hoje não têm o mesmo propósito de lutar contra as representações. Já estamos dentro

9 Romeo Castelucci, Diretor italiano de teatro experimental. Dirigiu Hey Girl! (2006) e Inferno (2009), dentre outros. disso, não é mais uma luta, faz parte. Porque já adotamos a ideia de que podemos ter uma presença e não uma representação cênica. Então, o fato de colocar hoje o real em cena surge para provocar o espectador, suscitálo a ver o espetáculo de outro jeito, a reagir de outra forma. Para resumir, diria que se a performance estava centrada no performer, o teatro hoje está voltado para o espectador. Em descobrir como acordar um espectador que está dormindo toda hora. Não é apenas o intuito de fazê-lo reagir só pelo prazer, mas fazê-lo reagir de forma inteligente, não só pela provocação. Claro que ainda existem espetáculos que trabalham somente com essa vontade de provocação. Vi em Nova York o Força Bruta ${ }^{10}$ [Fuerza Bruta], que é um espetáculo corporal meio Broadway, ele passa pelo corporal o tempo todo, pelo sensorial, mas não é contextualizado, enquadrado, não é interessante. Já em outros casos, existe uma contextualização, uma simbolização do que está colocado em cena. Porque se o real é mostrado de qualquer jeito, ele deixa de ser interessante.

\section{E o que seria esse enquadramento?}

Tem que haver uma dramaturgia, um contexto para que traga esse senso de estética. Por exemplo, a diferença entre o que vemos na Internetenumespetáculo é que na Internet não há o enquadramento. A violência, para ter algum sentido, precisa desse enquadramento, porque se for simplesmente colocada de forma bruta, se torna apenas soma, não faz diferença. Teve um caso que me impressionou de dois jovens adolescentes da Inglaterra que martirizaram um menino de cinco anos. 
Mas o que posso fazer com isso do ponto de vista simbólico? Essa é a violência bruta, existem vários exemplos disso. Para resumir, voltando ao domínio da estética, a violência tem que ser enquadrada de algum jeito para ter um sentido ou para nós conseguirmos dar algum sentido a ela. Para ela poder ser gerenciada intelectualmente, senão estamos paralisados, não podemos gerar nada com isso.

Você diz que o real hoje aparece na arte como uma tentativa de acordar o espectador, mas que a presença da violência em cena tem que ser enquadrada simbolicamente para fazer sentido. Ela seria então uma forma atualizada de despertar o senso crítico diante do que o público vê?

Sim, com certeza, mas talvez não seja isso o que aconteça. Porque é uma violência tautológica. A gente invoca a violência pela violência, um pouco como acontece na vida. Ela não provoca o espírito crítico do espectador. Só provoca uma reação sensorial. De rejeição ou de desgosto, mas não provoca uma reação crítica no espectador.

\section{Mesmo se estiver enquadrada?}

Para você despertar esse senso crítico, você precisa ter outro pensamento por cima disso e não somente evocar a violência pela violência na cena. Porque a violência corporal está limitada pela imagem que a gente projeta. Sendo que a violência evocada pela dramaturgia permite mais espaço de reflexão, traz vantagens a essa reflexão. Porque quando mostramos pessoas sangrando, a violência bruta, o que você está expressando além do ato por ele mesmo? Nesse caso, tudo o que o espetáculo fala é que existe violência. Então é bem limitado. A coisa mais importante no teatro é a função metafórica. E aí que o espectador intervém. É aí que a inteligência do espectador é solicitada. E, nos espetáculos de violência bruta, ela não é solicitada. Não estamos no domínio metafórico, estamos na realidade. Mas a realidade só é interessante quando está enquadrada e explicada. É por isso que os espetáculos de violência neles mesmos não me interessam. O que é interessante, como nos dois primeiros exemplos que dei, é o que envolve a cena, como isso é fechado. Voltando ao 11 de Setembro, o que me impressiona na fala do Stockhausen é o desaparecimento das mortes que os atentados causaram.

No final da palestra, você relaciona a fruição traumática com a catarse grega, a partir do livro de Paul Ardenne. Qual seria o elo entre uma coisa e outra e até que ponto ela cria certa alienação, como Brecht falava?

Acho que deve haver esse distanciamento, é o que falo do performer, se você está num espetáculo que é só o real, você está lá e tem que ter essa visão de fora para ficar interessante. Você tem que ter momentos de real e de ficção, esse vai-evem é que faz o espetáculo ser bom, abrir o pensamento. A teatralidade vem da divisão entre o espaço cotidiano e o espaço da cena. Dentro do espaço cênico também tem uma divisão, sobre o que é real material e o que é criado na cena. E o olhar do espectador sempre faz ida e volta - como uma agulha entre o real e a ficção. Ou o espaço cotidiano e o espaço cênico. O olhar é sempre duplo. E na violência de repente tudo fica chapado. Então você tem que sair dessa violência para entendê-la. E é muito importante esse vai-evem, ele está na base da experiência estética e da experiência teatral também. Porque se não tem isso, ou você está no real ou está no delírio. Como nos hospitais psiquiátricos, onde pessoas pensam ser o personagem o tempo inteiro. A experiência teatral é você ver no ator tanto a experiência do real quanto a da criação, ao mesmo tempo. Quando você olha um ator, você vê, ao mesmo tempo, que ele é de carne e osso e que está numa ficção. Por exemplo, se decido subir em cima da mesa e fazer um personagem, você, como espectador, tem duas opções: ou pensa que estou fazendo teatro - mas se 
pensar vai saber que pode detectar tanto o lado real quanto o jogo - ou você não faz essa distinção e vai para hospital e você está no delírio. Então, o olhar do espectador tem que ter essa dualidade e frente à violência é a mesma coisa. Mas, de repente, um dos aspectos é mais importante: o real. É o que chamo também de performatividade. Isso esmaga minha reação porque sou absorvida na coisa. Mas, para poder pensar sobre ela, tenho que sair, por isso falo de enquadramento sempre.

\section{E é essa absorção que você relaciona com a catarse?}

Sim, mas a catarse não é só pela absorção, pode ser também pelo caminho da reflexão. Ela permite gerar e compreender a violência, mas, ao mesmo tempo, expressar suas angústias.

Ao falar sobre a espetacularização dos atentados de 11 de Setembro, você remete à ideia de sociedade do espetáculo, de Guy Debord. Alguns grupos de teatro buscam explorar o real na ficção justamente para contrapor essa ideia, realizar um caminho inverso. Que tipo de relação você vê entre o real na cena contemporânea e essa espetacularização da sociedade?

Para começar, o real tem a sua lógica e o espetáculo tem outra. Quando se leva um para dentro do outro, há que se ter alguma atenção. Há duas formas de criar o espetáculo no real. Um exemplo para clarificar essa distinção: quando o grupo Royal de Luxe ${ }^{11}$ faz espetáculos em um espaço público, ele importa o espetáculo para o real. A companhia teatraliza o real. Mas há uma entidade teatral e uma entidade social que são distintas. A companhia estabelece pontes entre essas duas. E é daí que nasce o prazer do espetáculo. Quando Guy Debord fala da espetacularização do real, não é disso que

11 Royal de Luxe é uma Companhia francesa de teatro de bonecos de rua. Eles foram fundados em 1979 por Jean Luc Courcoult. se trata e não é disso que quero dizer. $\mathrm{O}$ que eu disse é que temos um contato com o real por meio do espetáculo e da imagem. Tudo o que foi dito sobre o 11 de Setembro dá razão ao Guy Debord. Porque o fato foi tantas vezes foi interpretado como espetáculo que nos esquecemos que foi um evento real com pessoas, com morte, com drama. Apenas se falou da imagem e da fotogenia do acontecimento. Baudrillard, ${ }^{12}$ que também foi citado na conferência, diz o mesmo que Stockhausen. Mas o tópico que me interessa nesse momento é falar da importação do real na cena.

\section{Por que?}

Eu acredito que esta é uma das marcas do teatro performativo atual. E é uma questão de dosagem entre o real e o espetáculo. Podemos nos interessar sobre diferentes aspectos do real que foram por opção importados para a cena, mas, agora, me interesso principalmente por alguns aspectos particulares que têm sido usados para a cena, ligados à morte. Não sobre a morte de alguém, senão pelo contrario, o momento mesmo da morte, dessa passagem para a morte. Acredito que esse é um momento espetacular, realmente. Mas a questão talvez seja como tornar esse momento espetacular de um modo digno, para que não seja espetacular stritcto sensu. Para que não seja apenas o efeito espetacular aquilo que se procura. Para que não busque o "voyerismo" do espectador. Para que possamos ir além da imagem. Talvez, contradizendo Debord, podemos dizer que o real espetacularizado importado para a cena é menos espetacular do que na vida. Talvez seja a forma de reencontrar a intensidade do evento. Porque, muitas vezes, nós vemos mortes e cenas de violência em documentários, mas quando esses materiais são colocados no espetáculo, eles reconquistam uma intensidade real.

12 Jean Baudrillard (1929 - 2007) foi um sociólogo e filósofo francês. Autor de Da Sedução (1979) e A troca impossível (1999), dentre outros. 
E como se dá esse processo de reconquistar uma intensidade real?

Alain Robbe-Grillet, um escritor do Novo Romance Francês e também crítico de arte, dizia que para redescobrirmos uma pintura, não podemos estar em um estado de inocência diante dessa obra, porque já nos habituamos a ver muitas reproduções. E, para descobrirmos uma autenticidade da pintura, é preciso retirar camadas. Para isso, é preciso escrever muito sobre a obra para reencontrarmos esse primeiro contato. Isso é uma inversão de Guy Debord. É uma inversão de um certo pensamento comum, vamos dizer, essa expectativa de que podemos ter esse encontro primeiro com a Gioconda ${ }^{13}$ quando finalmente formos ver o quadro no museu, apesar de termos tido inúmeros encontros anteriores em reproduções. E eu acredito, com afirma Debord, que a vida tem sido espetacularizada mesmo. E que é preciso despir as camadas do espetáculo para reencontrar a urgência do momento. E aquilo que faz o artista é precisamente procurar o coração do real, dessa urgência do momento.

\section{Alguns autores colocam a} performatividade como um elemento de aproximação entre arte e vida, enquanto a teatralidade teria função distanciadora. Você também percebe essa dicotomia?

Completamente. A teatralidade é um jogo de vai-e-vem entre o real e a ficção. $\mathrm{Na}$ performatividade, nós aderimos à ação, estamos dentro dela. É semelhante a quando vemos um jogo esportivo, em que estamos no movimento, na ação, no acontecimento. Mas para conhecer a teatralidade, é importante estarmos fora, pois é essa distância que permite o movimento de ir e vir. Winnicott ${ }^{14}$ escreveu $^{-}$ sobre o jogo. Ele explicou que, para a criança jogar, é necessário que ela crie um espaço diferente do real, do cotidiano, que ele chamou de espaço transicional. Quando a criança está dentro desse espaço, ela pode brincar. Quando está fora dele, está no real. Quando um ator leva o real para o jogo, ele não pode jogar. Ele tem que ver os dois espaços. Pois de forma contrária, ele está ou como ator no espaço transicional, ou só no exterior, no real. Mas, para manter sua posição de espectador, ele deve ser capaz de ficar nas duas posições. É por isso que quando há um acontecimento real no teatro, um acidente, ninguém faz nada. Se o ator cai, por exemplo, ou passa mal, ninguém faz nada, pois sabe que é ficção. Porque o espectador vê os dois: o real e o jogo. Se o espectador estivesse unicamente no real, quando visse o ator passar mal, ele interviria. Isso quer dizer que, para enxergar a teatralidade, é preciso haver uma distância. E é por essa distância ficcional que não se intervêm. Mas, na performatividade, o espectador está dentro. $\mathrm{O}$ espectador cola, adere ao acontecimento. E eu acredito que se existem muitos artistas hoje que utilizam o real em cena é para forçar o espectador a aderir ao espetáculo.

14 Winnicott (1979/1983). Psicólogo inglês.
13 La Gioconda ou, em francês, La Joconde, ou ainda Mona Lisa del Giocondo, é a mais notável e conhecida obra do pintor italiano Leonardo da Vinci. 